Rev. $A N P(L L$, n. 6/7, p. 47-55, jan./dez. 1999

\title{
A INTERTEXTUALIDADE E OS ESTUDOS LITERÁRIOS
}

\author{
José Luís Jobim*
}

RESUMO: Este trabalho discute a relação entre as práticas de produção textual acadêmica na área de Letras, no Brasil, e os conceitos de intertextualidade e originalidade, visando a colocar em questão o quadro de referências em que se insere esta relação.

PALAVRAS-CHAVE: intertextualidade; originalidade; textos acadêmicos.

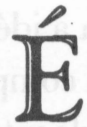

interessante notar como na área de Letras com freqüência manifestam-se opiniōes sobre a produção de textos acadêmicos que poderiam ser atribuídas ao Romantismo.

$\Lambda$ cobrança de "originalidade" nos trabalhos terminais de pós-graduação, por exemplo ${ }^{1}$, lembra-nos a representação do autor como demiurgo, responsável pela gênese absoluta daquilo que escreve - em outras palavras: como aquele que cria o texto do nada, de forma assemelhada a Deus criando o mundo ${ }^{2}$. Trata-se de uma representação dificilmente compatível com pelo menos dois fatos: 1) estes trabalhos terminais apresentam dezenas (algumas vezes mais de uma centena) de notas de rodapé e referências bibliográficas explícitas; 2) a intertextualidade, entendida aqui como um jogo de referências múltiplas a outros textos e contextos - na forma de influências, citações, alusões, paráfrases, reescrituras etc. -, é a regra e não

* Universidade Federal Fluminense - UFF e Universidade do Estado do Rio de Janeiro - UERJ.

1 O Regulamento específico do programa de pós-graduação em Letras da UFF, por exemplo, estabelece, no artigo 44 do capítulo VI ("Dos trabalhos terminais"), que "Para a obtenção do grau de Doutor é exigido um trabalho terminal original, fruto de atividades de pesquisa importando em real contribuição para a área de Letras".

2 Cf. JOBIM, J. L. A leitura e a produção textual: uma visão histórica. In: A poética do fundamento. Niterói: EDUFF, 1996. 
JOBIM, José Luís. A intertextualidade e os estudos literários.

a exceção na nossa produção acadêmica. Para sermos justos, isto é reconhecido mesmo no regulamento de alguns cursos de pós-graduação em Letras, quando estabelecem que "o aluno demonstrará domínio do tema escolhido, atualização bibliográfica e capacidade de sistematização" ${ }^{3}$. Nesse contexto, "atualização bibliográfica" pode significar a explicitação do tributo que o pós-graduando paga ao corpus de textos cujo conhecimento ele precisa demonstrar - corpus que tanto se presume ser delimitado por escolhas do passado quanto aberto a novas incorporaçōes.

Na graduação, a área de Letras também oferece uma formatação em que se valorizam algumas habilidades a serem adquiridas pelos discentes, que podem ser associadas à intertextualidade. $\Lambda$ s habilidades presumidas pela Comissão Nacional de Letras para os formandos, por exemplo, abrangem as atividades de leitura e escrita, implicando o desenvolvimento de uma competência intertextual. Inclui-se nessa pauta a idéia dos filtros culturais, através dos quais chegamos, na sala de aula, à compreensão da obra literária. $\Lambda$ ssim, em vez de imaginar que a atividade interpretativa é derivada apenas do contato direto com as obras, admite-se a mediação dos sentidos atribuídos pela tradição crítica e teórica que em diversos momentos tematizou a obra. Ou seja, admite-se a importância da apropriação crítica de diferentes perspectivas sobre a obra analisada. Também se destacam as habilidades de: "explorar as relações dos textos literários com outros tipos de discurso e com os contextos em que se inserem"; "relacionar o texto literário com os problemas e concepções dominantes na cultura do período em que foi escrito e com os problemas e concepções do presente"; "interpretar adequadamente textos de diferentes gêneros e registros lingüísticos e explicitar os processos ou argumentos utilizados para justificar sua interpretação" 4 . Tudo isso, ressalte-se, aponta para aspectos intertextuais.

3 Exigência para os alunos do Mestrado. Regulamento específico do programa de pós-graduação em Letras da UFF. Artigo 44, capítulo VI.

- Ministério da Educação. INEP. Portaria de 30 de janeiro de 1998. 
$\Lambda$ explicitação da intertextualidade entre a obra literária e os seus respectivos textos interpretativos, eleitos como modelares, não significa necessariamente - como se poderia alegar - a legitimação acadêmica de certo sentido atribuído à obra, com a exclusão de outros possíveis. Contudo, o que se teme é, muitas vezes, a produção de uma matriz interpretativa exclusiva e excludente, reguladora universal, paradigma a ser evocado sempre que se pretende julgar novas interpretações. $\Lambda$ ssim, começaremos por discutir as implicações dessa hipótese.

Se elejo um texto interpretativo como modelo legitimador dos que o seguem - aspirando a cobrar destes a correspondência com o que e como ele diz -, posso até produzir uma espécie de matriz de reiteração em um certo quadro de referências, por determinado período. Usar um texto interpretativo como norma, regendo o que devemos dizer sobre uma obra literária e como devemos dizê-lo, pode produzir, durante algum tempo, um efeito de naturalidade do sentido que se atribui à obra. Pode também gerar um parâmetro mais sólido para avaliação de textos interpretativos a serem produzidos, que poderão ser julgados à luz do modelo, de onde se derivariam as categorias de aprovação ou recusa. $\Lambda$ ssim, por exemplo, o aluno poderia com maior segurança invocar um paradigma a partir do qual configuraria sua interpretação, e teria sua capacidade de falar de uma obra literária confundida com o domínio de um corpus interpretativo, de uma fortuna crítica.

$\Lambda$ idéia de paradigma, além disso, nos afastaria da noção ingênua de que a interpretação é um ato privativo do sujeito - isto é, algo que concerne somente a ele e a mais ninguém -, porque trata-se de uma idéia que remete a critérios extra-subjetivos. Quando interpretamos um texto num sentido determinado, está implícita nesta atividade uma referência às normas que regulam a prática interpretativa vigente na comunidade de Letras, as quais de alguma maneira nos constrangem a seguir certos caminhos (em vez de outros), e a considerar estes caminhos como corretos. Contudo, mesmo quando existem modelos interpretativos que aspiram a funcionar 
JOBIM, José Luís. A intertextualidade e os estudos literários.

como regra, a questão da correspondência ou não ao que se supõe ser o sentido do modelo pode tornar-se um complicador. Isso porque a distinção entre o que corresponde ou nảo ao modelo dependerá da própria compreensão do modelo. Esta compreensão, se não deriva de vozes de autoridade (como o próprio autor do texto interpretativo, por exemplo), pode ganhar muitas variantes.

No entanto, ao se falar em modelo, não necessariamente se evoca um modelo positivo. Podem-se escolher textos modelares por sua negatividade. $\mathrm{O}$ que significa isso? Manuel Bandeira disse que aprendeu mais com os poetas ruins do que com os bons, porque com aqueles aprendeu o que não se devia fazer. $\Lambda$ ssim, determinados textos interpretativos podem servir como "modelos negativos" - como instâncias consubstanciadas em normas e princípios que não consideramos adequados à interpretação. (Poderíamos, por exemplo, trazer à sala de aula o Machado de Assis, de Sílvio Romero ${ }^{5}$, ainda que não concordássemos com uma linha sequer do que ele diz sobre o bruxo do Cosme Velho.)

Também se poderia supor que é o conhecimento tanto do que dizem certos textos quanto de como o dizem que se transforma em marca de classe para o discente, em sinal de sua inscrição na categoria dos "formados em Letras". $\Lambda$ ausência desse conhecimento seria avaliada como falta $\mathrm{e}$ potencialmente punível, já que, por exemplo, as notas tanto do exame nacional de cursos quanto dos concursos de acesso ao magistério provavelmente discriminarão entre os que têm acesso àquele conhecimento e os que não têm.

No entanto, embora compreendamos ser possível crer que um determinado texto interpretativo nos proporciona uma chave de sentido mais permanente para uma obra literária, a história da literatura nos oferece um vasto repertório de textos cuja pretensão o tempo sepultou. Isto porque, se é possível que determinada interpretação aspire à hegemonia ex-

5 Cf. Silvio Romero. Machado de Assis. Campinas: Ed. da UNICAMP, 1997. 
Rev. $A N P(L L L$, n. 6/7, p. 47-55, jan./dez. 1999

clusiva, efetivamente a sua própria reiteração já significa um deslocamento, uma diferença, uma deriva em relação à sua pretensa permanência. Em outras palavras, como o texto interpretativo também é reinterpretado, quando dele nos reapropriamos em sala de aula, seu sentido está em movimento.

Jean-François Lyotard, ao tratar da escrita hoje, afirma que um escritor pós-moderno está na situação de um filósofo: o texto que ele escreve, a obra que realiza não são em princípio governados por regras já estabelecidas, e não podem ser julgados por meio de um julgamento determinante - por aplicação a este texto, a esta obra, de categorias conhecidas. Estas regras e categorias seriam o que a obra ou o texto procura. Portanto, o escritor trabalharia sem regras. Ou melhor: ele trabalharia para estabelecer as regras do que já teria sido feito. Por esta razão o texto teria as propriedades do evento ${ }^{6}$.

Entretanto, o que a história da produção textual nos mostra é que há sempre instâncias anteriores ao texto (normas, práticas e tradições préexistentes, formas de representação etc.) que de alguma forma o condicionam, o que nos faz, pelo menos, suspeitar da idéia de que hoje não há regras preestabelecidas para a escrita, ou mesmo de que estas "regras" seriam o que o texto procura. $\mathrm{O}$ modo como se estabelecem as relações com estas instâncias anteriores paga um tributo pesado ao contexto em que se insere. É diferente, por exemplo, o quadro de referências para a leitura e a produção textual, se o analisamos no momento histórico em que a poética da emulação era hegemônica, ou na contemporaneidade, quando está vigente uma poética de originalidade e ruptura ${ }^{\text {? }}$.

Nliás, a ideologia moderna sobre a produção textual - ao valorizar a originalidade e a ruptura com modelos anteriores - gerou uma angústia da

6 Jean-François Lyotard. Le postmoderne expliqué aux enfants. Paris: Galilée, 1988. p. 26-7.

7 Para um desenvolvimento mais detalhado desse argumento, Cf. José Luís Jobim. A poética do fundamento. Niteró: EDUFF, 1996. Especialmente os capítulos 1 e 2. 
JOBIM, José Luís. A intertextualidade e os estudos literários.

influência, às vezes desmedida. Veja-se, por exemplo, essa carta de Mário de Andrade a Carlos Drummond de Andrade:

“(...) Agora raciocinemos no que você fala da minha influência sobre você. Em última análise, tudo é influência neste mundo. Cada indivíduo é fruto de alguma coisa. Agora tem boas influências e tem influências más. Além do mais se tem que distinguir entre o que é influência e o que é revelação da gente própria. Muitas vezes um livro revela pra gente um lado nosso ainda desconhecido. Lado, tendência, processo de expressão, tudo. O livro não faz que apressar a apropriação do que é da gente. Digo isso pra você se sossegar nesse ponto. Eu sofri muito com isso, Drummond. Via em mim influências dos outros, queria tirá-las e ficava sem nada. Mas aquela frase da Paulicéia não saiu ao atá, não. "Sinto que o meu copo é grande demais e ainda bebo no copo dos outros". Não tem dúvida que você faz coisa da mesma categoria que a minha. Ora, mesma categoria implica uma identidade qualquer. O que carece é você não ver influência nessa identidade, mas resultância da mesma categoria. Se os meus exemplos deslancharam alguma coisa em você, se lembre sempre que você nunca me olhou com mimetismo nem servilismo graças-a-Deus, porém me critica, me pesa, escolhe e ama o que é também seu. Amor; no sentido geral, isto é, isento de sexualidade, é uma questão de espelho. Este mundo está cheio de Narcisos. Nós todos.(...)" 8

É interessante observar que Mário escreve esta carta ainda em ambiente marcado pela estética da ruptura - derivada do ideário das vanguardas do início do século -, que funciona segundo uma lógica bem determinada: valoriza o "novo", o mais recente, a avant-garde, buscando ressaltar que a diferença em relação ao "passado" é positiva em si. O modus hodiernus serve como parâmetro para a depreciação do passado, numa atitude que é definida com muita propriedade por Mário:

"Toda tentativa de modernização implica a passadistização da coisa que a gente quer modernizar. Assim nos sujeitos indivíduos que tentam é natural, quase imprescindível a psicologia do revoltado" 9 .

8 Carta sem data, provavelmente de 1925. In: ANDRADE, Carlos Drummond de. A lição do amigo - cartas de Mário de Andrade. Rio de Janeiro: José Olympio, 1982. p. 31.

9 Trecho de entrevista para o Jornal A Noite, 12 dez. 1925. 
Rev. $A N P(L L$, , n. 6/7, p. 47-55, jan./dez. 1999

$\Lambda$ "passadistização" significa o enquadramento da literatura de antes na categoria de algo que deve ser ultrapassado pelo mais recente atitude congruente com a estética da ruptura, que usa a literatura anterior como modelo negativo. $\Lambda$ "psicologia do revoltado" é assumida não como fenômeno ligado à esfera esfera mais intimamente subjetiva, mas como papel a ser desempenhado pela função autoral moderna ${ }^{10}$.

Mário percebe que a intertextualidade - marca registrada - está presente mesmo nos textos "modernos". Ele formula uma tese mais genérica sobre esse fenômeno ("Em última análise, tudo é influência neste mundo. Cada indivíduo é fruto de alguma coisa"), e busca precisar uma explicação consistente com o princípio, derivado do Romantismo, que considera o texto expressão da subjetividade autoral:

"Além do mais se tem que distinguir entre o que é influência e o que é revelação da gente própria. Muitas vezes um livro revela pra gente um lado nosso ainda desconhecido. Lado, tendência, processo de expressão, tudo. O livro não faz que apressar a apropriação do que é da gente" ${ }^{11}$.

Em vez da idéia de imitação, que ressaltaria a exemplaridade do outro, Mário sintomaticamente adota a tese de que o outro serve ao sujeito para que descubra o que todavia era seu, ainda que ele não soubesse. $\Lambda$ ssim, ele pode empregar a palavra "exemplo", para qualificar-se perante Drummond, sem que isso tenha um sentido negativo (para um ambiente estético modernista), pois seu exemplo não é visto como algo a ser imitado ou emulado, mas, isso sim, como elemento que aciona um componente que já existia na subjetividade autoral sobre a qual o exemplo atua. Por isso o descarte explícito do "mimetismo" (igualado sintaticamente ao "servilismo") na identificação da produção textual de Drummond, e o desta-

10 Sobre a função autoral, cf. Michel Foucault. Qu'est-ce qu'un auteur? Paris: Bulletin de la Societé Française de Philosophie, 1969.

11 Carta sem data, provavelmente de 1925. In: ANDRADE, Carlos Drummond de. A liçäo do amigo - cartas de Mário de Andrade. Rio de Janeiro: José Olympio, 1982. p. 31. 
JOBIM, José Luís. A intertextualidade e os estudos literários.

que dado ao fato de que a apropriação efetuada por esse autor é fruto de uma escolha crítica, através da qual só se incorporaria ao seu texto aquilo que de alguma forma já pertencesse antes à subjetividade autoral. Então, o que poderia ser visto negativamente como referência identificante, mimesis discursiva, parasitismo textual, modelização (ou qualquer outro sintagma semelhante), passa a ser visto positivamente, pois se argumenta que aquilo que se incorpora não é algo tomado de empréstimo: "é também seu".

"Se os meus exemplos deslancharam alguma coisa em você, se lembre sempre que você nunca me olhou com mimetismo nem servilismo graças-aDeus, porém me critica, me pesa, escolhe e ama o que é também seu" ${ }^{12}$.

Porém Mário possuía também uma consciência aguda do tributo que pagava aos outros: "Via em mim influências dos outros, queria tirá-las e ficava sem nada". Talvez uma de nossas diferenças em relação a esse pensamento de Mário seja o fato de que vemos, sim, influências dos outros, mas, em vez de "querer tirá-las", preferimos atribuí-las a uma intertextualidade virtualmente infinita, em relação à qual as convenções e protocolos nos trabalhos acadêmicos da área de Letras - citações, paráfrases, rodapés etc. - são apenas o exemplo mais visível.

ABSTRACT: This article deals with the academic practices of writing in brazilian literary studies, focusing mainly the ideas of intertextuality and originality and their context.

KEYWORDS: intertextuality; oeriginality; academic writing.

12 Carta sem data, provavelmente de 1925. In: ANDRADE, Carlos Drummond de. A lição do amigo - cartas de Mário de Andrade. Rio de Janeiro: José Olympio, 1982. p. 31. 
Rev. ANPOLL, n. 6/7, p. 47-55, jan./dez. 1999

\section{BIBLIOGRAFIA}

ANDRADE, Carlos Drummond de. A lição do amigo - cartas de Mário de Andrade. Rio de Janeiro: José Olympio, 1982.

FOUCAULT, Michel. Qu'est-ce qu'un auteur? Paris: Bulletin de la Societé Française de Philosophie, 1969.

JOBIM, J. L. $\Lambda$ poética do fundamento. Niterói: EDUFF, 1996.

LYOTARD, Jean-François. Le postmoderne expliqué aux enfants. Paris, Galilée, 1988.

Universidade Federal Fluminense. Instituto de Letras. Coordenação de pós-graduação em Letras. Regulamento específico do programa de pós-graduação em Letras da UFF. Niterói: UFF, 1997.

Ministério da Educação. Instituto Nacional de Estudos Pedagógicos. Portaria de 30 de janeiro de 1998.

ROMERO, Silvio. Machado de Assis. Campinas: Ed. da UNICAMP, 1997. 